\title{
REFLECTIONS
}

\section{Home Care: \\ A Key to the Future of Family Medicine?}

\author{
Steven H. Landers, MD, MPH \\ Department of Family Medicine, Case \\ Western Reserve University School of \\ Medicine and University Hospitals of \\ Cleveland, Cleveland, Ohio
}

\begin{abstract}
This essay is about my transition from family medicine residency into house call/ home-based primary care practice. Though some aspects of making home visits have been difficult and uncomfortable, I have found a higher level of satisfaction and sense of purpose than I had as a resident in a traditional outpatient clinic. This enhanced satisfaction is, in part, due to my discovery that a lower-volume, time-intensive house call practice is a more appropriate way than the brief office visit to care for older patients who have multiple morbidities. In light of the aging population, advances in portable medical technology, and changes in Medicare reimbursement, home care could become a key to the future success and ongoing relevance of family medicine.
\end{abstract}

Ann Fam Med 2006;4:366-368. DOI: 10.1370/afm.550.

$\mathrm{H}$ e popped out the front door, came down the rotting porch, and took the wrench from my hand. "A white man in a shirt and tie shouldn't be changin' a flat," he said. I awkwardly stepped back and wiped the sweat off my brow. He was a short black man in a wellworn navy blue mechanic's outfit, his baseball cap backwards with the rim flipped up. He came too close too quick and was laughing like he was drunk. I panned the block—vacant lot, boarded up house, cars passing, drivers staring. A young woman in tight blue shorts and a half-length top slowly walked past. He stared her down. "You all think every woman walkin' this street is hookin," she said, and kept walking. She headed toward the corner store 2 blocks up, one of the "beer, lotto, cigarettes," places that are scattered throughout this part of town, where several people were standing.

This moment quickly became the most uncomfortable in my first 3 months on the job. I just finished my family medicine residency at Case Western Reserve University/University Hospitals of Cleveland in June, and I decided to stay on to help start a new house call/home primary care program. Our program is similar to others that have sprouted up around the country in recent years, possibly in response to the aging population and higher Medicare-allowable reimbursement for home visits. ${ }^{1}$ I work closely with a nurse-practitioner, and we try and coordinate our care with home health companies and community aging agencies.

Fortunately, my car trouble has been limited to that single episode. There have been other inconveniences-it was a hot summer, most of my patients don't have air conditioners, and I'm a pretty big guy who easily sweats. The heat and sometimes the odors, such as the stench of tobacco and urine, can be unpleasant. But, in many ways I have felt more comfortable doing home visits than I ever did in my residency continuity clinic. Though my medical school and residency training did not emphasize home care and house calls, I'm finding that the home is a natural place for our specialty. We have the social conscience to part with the comfort 
and familiarity of the office, we are trained to facilitate family problem solving, and we are a modern extension of the traditional generalist physicians that thrived in the home. As the United States seeks ways to address the health care needs of an aging population, elevating the role of family physicians in home care could be a satisfying intervention for both the health care system and physicians.

Most of my visits typically take 30 to 40 minutes, and it's hard not to linger a bit longer to talk about the weather, a book on the table, or a photograph on the wall. I'm learning very practical things about my patients, such as how they manage their medicines and diet, and I'm meeting family members and neighbors to enlist as a caregiving team who would not be present at an office visit. This deeper understanding of my patients has empowered me to provide more relevantand likely more effective-preventive and chronic disease counseling and care coordination. Away from my office, as a guest in patients' homes, I am forced not to rush. Instead of standing above them, I usually must sit beside them on their couch or even on their bed, so we become closer. I've had more hugs and held more hands in 3 months than I did in 3 years. I feel like I'm caring for my patients and that they care for me.

The lectures about family dynamics, patient-centered care, and the community health curriculum are becoming more relevant, whereas just a few months ago in my residency continuity clinic, they didn't always add up in the 15-minute "get 'em in and out" clinic visits I was becoming accustomed to. In that world, I often dreaded a sick patient with multiple problems, family conflict, and dementia. The number of medications, unresolved issues, and consultants could make my head spin. These patients were too hard to fit into the clinic schedule. "Please let it be an introverted 30-year old with a mild case of allergic rhinitis," I would sometimes think as I knocked on the door. I became a family doctor because I wanted to help people in need, but for me, those who were most needy and vulnerable became burdensome in 10 - to 15 -patient half-day sessions. Experiencing sick patients as burdensome was very unsatisfying, and feeling burdensome is likely unsatisfying for the patients, too. After waiting for a ride, spending sometimes hours in the waiting room, and leaving with unresolved concerns, patients and caregivers are often left to pick up the pieces at home through an automated telephone tree or, even worse, the emergency department.

According to the undercurrents I hear from students and colleagues, enthusiasm for high-volume office-based family medicine is waning. Clearly, our specialty is in transition, and the concerns I've raised are not new. Some are addressed in the Future of Fam- ily Medicine project report, and I'm optimistic that elements of the New Model will make family medicine offices more satisfying places for doctors and patients. ${ }^{2}$ I think the home could be another key to the future of family medicine. The US population of those older than 65 years is expected to grow to more than 70 million by 2030, and many will have physical and cognitive disabilities that make it difficult for them to leave their homes. ${ }^{3}$ I believe the home is an ideal place to care for the most frail, most complex, and most costly older patients, and there are published studies that support this conviction. ${ }^{4-6}$ Family physicians working within multidisciplinary teams are ideal for this job. In light of recent downward trends of internal medicine resident interest in primary care and geriatrics training, there is an enormous opportunity for family physicians to rise up to meet this oncoming societal need.

In addition to providing better care in a more satisfying way, home care can be financially viable. In 1998 Medicare increased the allowable reimbursement for home visits by almost 50\%. In 2005 the allowed charge for a detailed visit to an established patient was about $\$ 110 .^{7}$ Medicare also allows physicians to charge for home care plan certification and oversight for homebound patients receiving nursing and rehabilitation services. Furthermore, although the volume of a home care practice is less than that of an office, the overhead is less. These factors appear to be influencing clinicians to provide more home care, as reflected by the rapid increase from 1998 to 2004 in the volume and charges for house calls. ${ }^{1}$ By using miniature computers, cellular telephones, mobile imaging, portable electrocardiograms, pulse oximeters, and other point-of-service diagnostics, the physician doesn't need to step backward from the technology of the modern medical practice. ${ }^{8}$ Making house calls full time is not for everyone, but doing more than a token visit and putting an emphasis on home care may be possible for many practices.

In his 1997 Nicholas J. Pisacano Lecture, Ian McWhinney made an impassioned plea for family medicine to "return to our roots" by making home visits. McWhinney reminded us that, "The home is where the family's values are expressed," and that, "There is deep symbolism in the home visit.... It says 'I care enough about you to leave my power base ... to come and see you on your own ground.' The symbolism is especially strong in the care of the dying." ${ }^{\prime \prime}$ In light of the aging population, advances in technology, and recent changes in Medicare reimbursement, this return to the home may now be possible. In fact, embracing home care may be a key part of the ongoing relevance and success of our specialty.

To read or post commentaries in response to this article, see it online at http://www.annfammed.org/cgi/content/full/4/4/366. 
Key words: House calls; home visits; home care services; family practice

Submitted July 26, 2005; submitted, revised, January 4, 2006; accepted January 10, 2006.

Funding support: This article was supported in part by the National Institutes of Health, National Institute of Child Health and Human Development, Multidisciplinary Clinical Research Career Development Programs grant K12 HD049091.

\section{References \\ 1. Landers SH, Gunn PW, Flocke SA, et al. Trends in house calls to Medicare beneficiaries. JAMA. 2005;294:2435-2436. \\ 2. Martin JC, Avant RF, Bowman MA, et al. The Future of Family Med- icine: a collaborative project of the family medicine community. Ann Fam Med. 2004;2(Suppl 1):S3-S32. \\ 3. Besdine R, Boult C, Brangman S, et al. Caring for older Americans: the future of geriatric medicine. J Am Geriatr Soc. 2005;53:S245-256.}

4. Hughes SL, Weaver FM, Giobbie-Hurder A, et al. Effectiveness of team-managed home-based primary care: a randomized multicenter trial. JAMA. 2000;284:2877-2885.

5. Stuck AE, Egger M, Hammer A, Minder CE, Beck JC. Home visits to prevent nursing home admission and functional decline in elderly people: systematic review and meta-regression analysis. JAMA. 2002;287:1022-1028.

6. Stuck AE, Aronow HU, Steiner A, et al. A trial of annual in-home comprehensive geriatric assessments for elderly people living in the community. N Engl J Med. 1995;333:1184-1189.

7. Centers for Medicare and Medicaid Services. Medicare Physician Fee Schedule Look-Up. Available at: http://www.cms.hhs.govlphysicians/mpfsapp. Accessed: 1 November, 2005.

8. Taler G. House calls for the 21 st century. J Am Geriatr Soc. 1998;46:246-248.

9. McWhinney IR. Fourth annual Nicholas J. Pisacano Lecture. The doctor, the patient, and the home: returning to our roots. J Am Board Fam Pract. 1997;10:430-435.

\section{Annals of Family Medicine Resident Research Supplement Call for Papers and Reviewers}

The Annals of Family Medicine seeks both research manuscripts and peer reviewers for a supplement devoted to research conducted by family medicine residents. The supplement is sponsored by the American Academy of Family Physicians Foundation.

Volunteer Reviewers. We encourage residents, residency faculty members, and others interested in nurturing resident research to contribute by reviewing 1 to 2 resident manuscripts in their areas of interest and expertise. To volunteer, please e-mail ressupp@musc.edu, giving your: (1) name ${ }_{i}(2)$ role: resident, residency faculty member, or other ${ }_{i}(3)$ methods expertise: quantitative and/or qualitative methods $s_{i}$ and (4) interest in reviewing manuscripts on clinical, quality improvement, community, health services, educational, or other research. We will send instructions on how to conduct a helpful peer review.

Submit Manuscripts. Manuscripts must be based on original work conducted while the lead author is/was a resident in a family medicine training program. They must describe original research that contributes new, transportable knowledge (excluding case reports, nonsystematic reviews, or essays). Manuscripts must follow the instructions for authors, available at http://annfammed.org/misc/ifora.shtml. The deadline for submission of manuscripts is March 1, 2007. Those submitted earlier will have priority in the review process.

Submit manuscripts to: ressupp@musc.edu.

Do not submit manuscripts for this supplement directly to the Annals.

Review Process. Guest editors Peter J. Carek, MD, MS, and Arch G. Mainous III, PhD, of the Medical University of South Carolina will coordinate initial peer review by reviewers who volunteer in response to this announcement. Based on this initial review, they will select manuscripts for formal peer review by the Annals. We will invite authors of the selected papers to submit a revised manuscript for possible inclusion in the supplement. The anticipated publication date of the supplement is January 2008. 